\title{
Aproximación al estudio de las obras de arte contemporáneo
}

\author{
Emilio Ruiz de Arcaute \\ Servicio de Restauración de la \\ Diputación Foral de Alava
}

\section{Resumen}

Se da un repaso a diferentes tipos de aproximación técnica a la obra de Arte Contemporáneo, comenzando por la obligación moral del conservador-restaurador de conocer y respetar las obras sobre las que trabaja. Se indica qué aspectos hay que tener en cuenta principalmente, haciendo hincapié en la importancia de la recopilación de información sobre las técnicas y los criterios de los artistas y en la metodología de los estudios científicos. Se comienza por la revisión de las fuentes documentales, como el contacto con el autor, los cuestionarios a los artistas, la realización de vídeos, la revisión sus escritos y documentos o las fuentes fotográficas, por ejemplo. También se repasan los estudios analíticos, los ensayos con materiales, etc., intercalando experiencias $y$ ejemplos prácticos concretos y las conclusiones que se pueden extraer en dichos casos.

\section{Palabras clave}

Técnicas / Criterios / Encuesta del G.E.T.C.R.A.C. / Fuentes documentales / Estudios Técnicos / Ensayos / Probetas

\section{Introducción}

Existe una gran coincidencia en torno a la complejidad material del arte moderno y su incidencia en la conservación de numerosos obras I. También se constata fácilmente la importancia de lo conceptual como uno de los factores determinantes en muchas de estas creaciones. Pero hasta hace unos años, cuando un restaurador formado en una visión clásica del arte, se enfrentaba a los problemas presentados por la conservación de una obra de arte moderna, se solían cometer errores técnicos por un incorrecto enfoque del problema y un desconocimiento de la naturaleza material y conceptual de la obra.

Quizá uno de los problemas fuera que no se valoraba adecuadamente la calidad o el interés de las obras modernas. La formación en Restauración ha pecado durante mucho tiempo de un excesivo enfoque en lo clásico. Se ha valorado sólo lo que cumplía una serie de cánones estilísticos o acumulaba una antigüedad suficiente, despreciando o infravalorando las obras más recientes.

Nunca se ha hecho suficiente hincapié en la responsabilidad moral del Conservador-Restaurador de conocer y respetar profundamente los objetos que se ve obligado a tratar. Conocer supone no sólo tener unas nociones básicas, sino investigar, observar detenida y profundamente, registrar toda información o incidencia, etc. Respetar implica no enjuiciar, no criticar, tener una visión neutral sobre la obra. El restaurador es un técnico no un crítico de arte y sólo desde el respeto y la asepsia se puede enfocar correctamente la investigación y el análisis técnico y conceptual, necesario para el conocimiento de una obra de arte moderno.

Sólo se desprecia lo que se desconoce y si la formación de los técnicos se centra en lo clásico, puede adolecer de un cierto desprecio hacia lo contemporáneo, por eso, solamente abriendo los campos de la preparación y reforzando las capacidades investigadoras se prepararán especialistas que puedan afrontar correctamente la intervención en todo tipo de obras y más concretamente en el área contemporánea.

Aunque se ha avanzado mucho en el examen cientifico de las obras, en el caso del arte moderno y contemporáneo, la proximidad histórica, la velocidad de las transformaciones estilísticas y la incorporación de nuevos materiales, en muchos casos no ha dado tiempo a una seria reflexión que adapte los métodos y técnicas de estudio a esta realidad. Por eso creo que 


\author{
Sería conveniente contar con especialistas formados y \\ mentalizados para enfrentarse al estudio de las obras de arte \\ desde una visión forense. Profesionales capacitados tanto para \\ el estudio técnico, el ensayo y la analítica, como para la \\ investigación de la historia material de la obra, de los \\ planteamientos creativos de los artistas, etc. Especialistas \\ capaces de estudiar y conocer tanto los aspectos materiales \\ como los conceptuales de cada obra
}

hay que seguir insistiendo en la necesidad de fomentar el estudio y la investigación en el arte contemporáneo. Sería conveniente contar con especialistas formados y mentalizados para enfrentarse al estudio de las obras de arte desde una visión forense. Profesionales capacitados tanto para el estudio técnico, el ensayo y la analítica, como para la investigación de la historia material de la obra, de los planteamientos creativos de los artistas, etc. Especialistas capaces de estudiar y conocer tanto los aspectos materiales como los conceptuales de cada obra, para poder plantear una correcta estrategia de conservación preventiva o de intervención.

Pero ¿cuáles son los aspectos que debe conocer y, por tanto, las cuestiones sobre las que debe recabar información o necesita investigar?. Dada la Heterogénea producción moderna pueden ser muchas las lagunas que tengamos sobre la obra, su génesis, su carácter conceptual, sus materiales, etc. Por eso también pueden ser muchos los campos de estudio.

En primer lugar, se han de estudiar los materiales y técnicas, teniendo en cuenta otras producciones, lo que nos aclarará sobre las preferencias del artista, su evolución técnica con el paso del tiempo, etc., interesándose igualmente por los motivos de sus elecciones de materiales (por su calidad plástica, por su aspecto o textura, por su facilidad de manejo, por su significado social o por motivos económicos o de escasez de otros materiales).

En este sentido, convendría insistir en la necesidad de conocer no sólo los materiales sino también las marcas de los productos y su fecha porque esto ayudará a relacionar la experiencia de unas obras con otras, de unos artistas con otros, de unos productos con otros.

Es muy frecuente que los artistas cuenten con ayudantes y colaboradores estables o más o menos ocasionales. El grado de participación del artista en la realización material de la obra es otro aspecto a tener en cuenta. Muchos creadores se limitan al diseño del proyecto, dejando la ejecución física a colaboradores o técnicos ajenos. Estas actitudes pueden ser determinantes a la hora de intervenir sobre una obra deteriorada.

En relación con la parte material de cada obra, se deben considerar los hábitos de trabajo del artista, los plazos y la velocidad de ejecución de sus obras. No es lo mismo la superposición rápida de empastes que dejarla reposar durante días o semanas antes de seguir trabajando sobre ella. La velocidad de intervención aparece reflejada en muchas ocasiones en la aparición de ciertos problemas de conservación de la obra. Por otro lado, si se trabaja simultáneamente en varias obras podemos encontrar coincidencias estéticas o técnicas y comparar su comportamiento tras el paso del tiempo para determinar si los deterioros son debidos a la técnica de ejecución, a los materiales empleados o, por el contrario, se pueden achacar a agentes externos independientes en cada caso.

Debemos conocer igualmente lo que denominamos "historia material de la obra", es decir, todo tipo de incidencias y vicisitudes sufridas por la obra desde su creación hasta nuestros días. Aquí se consideran todos los traslados, exposiciones y manipulaciones. Se trata de conocer al máximo cómo ha sido manipulada la obra, si ha sufrido accidentes, si se ha expuesto a condiciones de riesgo, si ha sido restaurada, incluso merece la pena tener en cuenta el trato de las obras en el taller del artista.

Todas estas cuestiones tienen que ver con la obra, su técnica y proceso de creación. Pero por otro lado hay que investigar directamente sobre las características de los materiales que pueden ser empleados en la creación de obras de arte y su comportamiento con el paso del tiempo, teniendo en cuenta como le afecta su uso y exposición.

Se deben desarrollar ensayos de comportamiento, que nos indiquen la resistencia de los distintos materiales. La vida de una obra de arte moderno suele estar sometida a múltiples traslados y exposiciones que suponen un gran estrés para la misma. Dependiendo de su naturaleza y complejidad material, los 
límites de resistencia de las obras serán mayores o menores, por eso es necesario conocer su respuesta ante las circunstancias a las que va a ser sometida, mediante la realización de pruebas. Aunque contemos con indicaciones del fabricante, no podemos conformarnos con ellas, ya que si bien el proceso de fabricación industrial suele incluir la realización de ensayos de envejecimiento y la superación de numerosos estándares, los criterios de evaluación de los mismos están pensados para periodos de tiempo limitados, de 20 o 25 años por ejemplo, mucho más cortos que lo que se espera de una obra que se integra en el patrimonio de una colección.

Finalmente necesitamos conocer los criterios de los artistas con respecto a la exhibición, manipulación y restauración de su obra. Tenemos la ventaja de la proximidad temporal de muchos creadores que aún están vivos o contamos frecuentemente con familiares, herederos, colaboradores y amigos que pueden informarnos de sus preferencias. Sin embargo también contamos con algún inconveniente, como la frecuente contradicción entre lo que el artista pretende para su obra y las posibilidades reales de conservación de ésta.

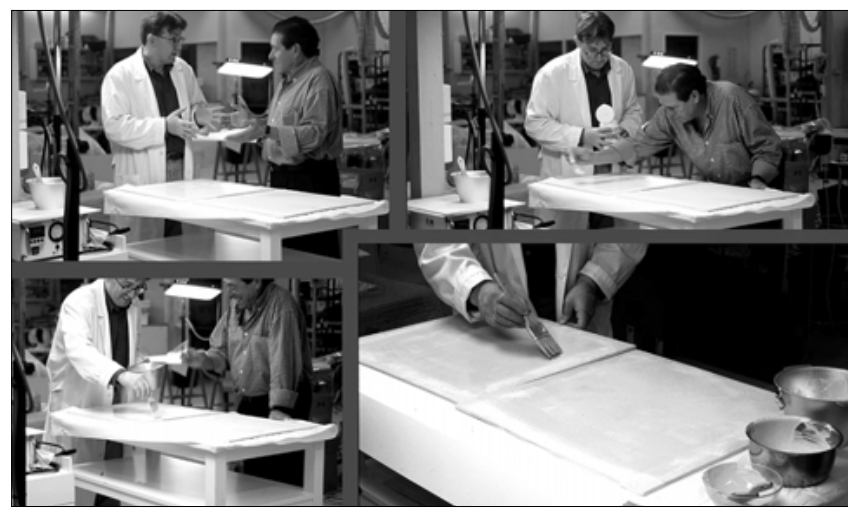

I. Realización de probetas junto con el artista Rafael Lafuente.
Si el artista es libre de trabajar con cualquier técnica y utilizar cualquier material en su proceso creativo, desconozca o no su durabilidad o compatibilidad entre ellos, el restaurador está obligado a conocer los materiales que el artista emplea y aquellos con los que él mismo trabaja. Su responsabilidad profesional hace necesario que utilice las técnicas más respetuosas o menos agresivas con el contenido de la obra y los materiales que envejezcan mejor y afecten menos a las mismas. Debe conocer todo lo posible sobre el artista, sobre su obra y sobre las técnicas y los materiales que emplea. En definitiva el restaurador está obligado a conocer el quién y el qué, el cómo, el cuándo y el porqué, el con qué y el hasta cuándo.

\section{El acercamiento al artista y su obra}

Como el conservador-restaurador tiene que ser un especialista que está, por ello, obligado a conocer y respetar profundamente el objeto de su trabajo, debe estar capacitado para una aproximación investigadora a la obra de arte.
Sabemos qué tenemos que conocer pero falta por definir dónde podemos obtener esta información, en qué fuentes podemos documentarnos, cómo podemos acceder a ella para averiguar los datos materiales y los planteamientos más teóricos, con vistas a establecer una estrategia de intervención deontológicamente correcta y técnicamente adecuada a cada caso.

\section{El contacto directo con el artista}

La mejor forma de obtener información sobre el artista y su obra es recurrir al contacto directo con éste. El contacto directo nos permite la obtención de una información completamente fiable y conocer exactamente los materiales o la forma de preparación y aplicación de los mismos, sin necesidad de realizar costosas y en ocasiones no concluyentes pruebas analíticas.

Siguiendo las indicaciones del artista e incluso con la participación directa de éste, podremos confeccionar probetas que reproduzcan los materiales, los productos y marcas, así como la técnica por él empleada, para realizar posteriormente con ellas ensayos o pruebas de tratamiento. Esta opción de trabajo previo sobre probetas de ensayo, está especialmente indicado para aquellas obras que presentan alguna complicación especial por la textura, los materiales empleados o las condiciones de acabado impuestas por el artista, puede abaratar el coste de las intervenciones y sobre todo asegurar la elección del método más adecuado en cada caso, por eso siempre que podemos incorporamos esta metodología de trabajo en casos semejantes (Foto I).

Aunque existen otros sistemas, como los cuestionarios a artistas, que nos permiten tener un conocimiento aproximado de sus apreciaciones, opiniones y preferencias sobre los criterios de intervención o sobre las técnicas que ha empleado, dado que cada obra puede ser diferente, los cuestionarios deben considerarse en principio como un elemento indicativo. Sólo la consulta directa al artista nos revelará los datos reales y lo que éste prefiere para la conservación de cada obra concreta. De hecho con alguna frecuencia nos encontramos con que el artista ha variado de opinión respecto a lo expuesto anteriormente o sus planteamientos eran genéricos y no se pueden aplicar a una obra determinada. Por eso, siempre que el artista esté vivo, se debe intentar contactar con él.

Resulta revelador, cuando se recaba información sobre intervenciones que han seguido las indicaciones del artista, contrastarlas con sus opiniones anteriores, cómo ha planteado el tratamiento, cómo y quién lo ha llevado a cabo o cuál es la importancia que ha dado a los daños de la obra.

En ocasiones los aspectos materiales de una obra tienen sólo una importancia relativa. El contenido social o el mensaje es más transcendente que el medio con el que se expresa. Un claro ejemplo de esto lo podemos apreciar en el "Bosque Animado" de 
Ibarrola. A caballo entre el Land Art, con claras connotaciones ecologistas, y el misticismo mágico de las fuerzas de la naturaleza, situado en un paraje próximo al santuario paleolítico de Santimamiñe, Ibarrola realiza su obra de Oma a desde 1984 hasta 1990. Esta obra, que es visitada anualmente por miles de personas y ha sido utilizada en campañas de promoción turística del país Vasco, pertenece a la Diputación Foral de Vizcaya desde esta última fecha.

El bosque de Oma integra naturaleza y arte, como otras obras de artistas contemporáneos integrados en el Land Art o Arte Ecológico, desprovista en un principio de un carácter temporal ya que se realiza originalmente y a lo largo de varios años, sobre árboles de un bosque que no pertenecían a lbarrola y estaban destinados a su aprovechamiento comercial. Un tipo de propuesta escasa en el panorama artístico español que se ha integrado perfectamente en los recorridos turísticos y naturalistas de la ría de Guernica (reserva natural del Urdaibai), se ha convertido en la obra más emblemática del artista, por lo que éste ha seguido trabajando en el mantenimiento de la misma a pesar de que la Diputación adquiriera el bosque.

Pero como tantas otras cosas en el País Vasco, esta obra ha sufrido el ataque de fanáticos del entorno de ETA. El último, que ha consistido en la tala de dos de los árboles pintados y la agresión mediante hachazos y pintadas de otros casi setenta, ha necesitado de una importante restauración bajo la supervisión de Agustín Ibarrola. Esta intervención se ha realizado como consecuencia de un convenio de colaboración entre la U.P.V. y la Diputación Foral en el que ha participado un equipo de cartógrafos, biólogos y restauradores, estos últimos a las ordenes de Pilar Bustinduy ${ }^{2}$

No es la primera vez que alguna obra sufre un ataque vandálico. "La Piedad" de Miguel Ángel, y "el Guernica" de Picasso son dos ejemplos famosos. Sin embargo en esta ocasión la agresión a la obra no sólo pretende dañarla, sino que principalmente trata de atacar a su creador, intenta hacer daño directamente a Agustín Ibarrola.

ETA ha elegido esta obra como símbolo de todo aquello que detesta. Así el arte, y más concretamente una obra que trata de conectar armoniosamente al hombre con la naturaleza y quizá al hombre actual con su antecesor que pintó las cuevas de Santimamiñe, se convierte en símbolo de lo que ETA pretende destruir. En ocasiones, las obras trascienden involuntariamente el mensaje pretendido por su autor o lo puramente estético, convirtiéndose en símbolos. La agresión contra esta obra aumenta su valor simbólico y la transforma en un icono político del sufrimiento, del callado martirio de una parte de la sociedad y de la cultura vasca.

Sabemos que el máximo ataque posible al derecho moral del artista es precisamente la destrucción total o parcial de su obra. En la restauración del bosque

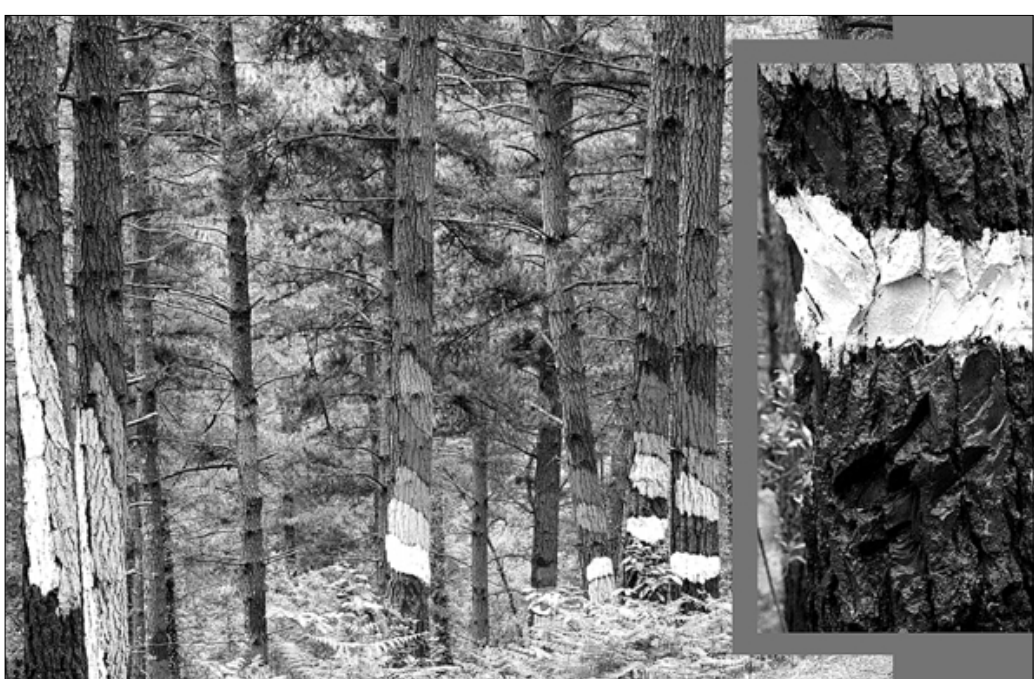

animado, Ibarrola ha querido disimular los cortes y reconstruir los colores, integrando las cicatrices de la historia de la obra en su contenido (Foto 2).

Por la encuesta del G.E.T.C.R.A.C. realizada en |99|, sabíamos que Ibarrola le otorgaba una importancia relativa a la conservación de sus obras, que si necesitan un tratamiento han de intervenirse siguiendo los criterios del restaurador de la colección, que según el tipo de obra de que se trate se deberá optar por alguna de las distintas posibilidades, desde la mera conservación hasta la sustitución. En el caso del bosque de Oma, el artista sin embargo se ha implicado mucho más que en otras de sus obras, teniendo en cuenta siempre las necesidades de su correcto mantenimiento, a pesar de que en principio fue una obra que pudiéramos considerar como de naturaleza efímera.

\section{Las encuestas del G.E.T.C.R.A.C.}

Como respuesta a la complejidad material de las creaciones modernas, desde hace bastantes años, varios centros de restauración y museos se plantearon la necesidad de recopilar información sobre estos aspectos, mediante la realización de cuestionarios a los artistas $^{3}$. En la mayor parte de los casos se han enfocado como documentación técnica sobre obras concretas que ingresaban en las colecciones o en los talleres de restauración. Se suele interrogar al artista sobre los materiales y técnicas de dicha obra, dejando de lado otras obras. En ocasiones el cuestionario se realizaba como un trámite previo a la adquisición, se concebía como un indicador de su calidad técnica que orientaba sobre los problemas que en el futuro podía presentar una pieza, para aconsejar o desaconsejar su compra. Una labor alejada de las obligaciones deontológicas del conservador-restaurador, que no debe juzgar la calidad del arte contemporáneo, ni desde el punto de vista estético ni del técnico.

Partiendo de este tipo de cuestionarios planteamos en 1988, sobre la base de la encuesta que se estaba llevando a cabo en el Servicio de Restauración de la
2. Detalles del Bosque de Oma de Agustín Ibarrola. Se aprecia el detalle de alguna zona atacada tras la restauración. 

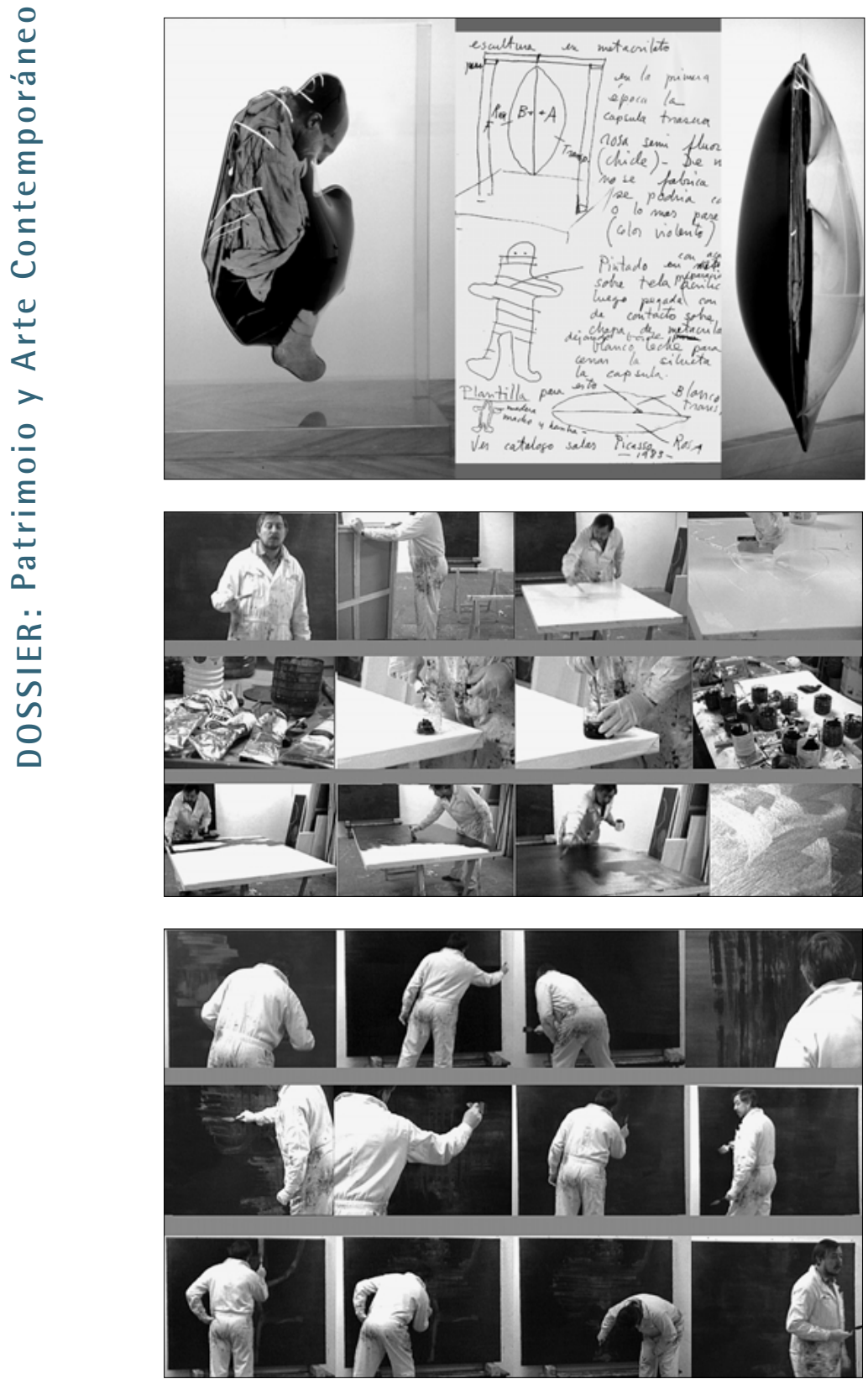

3. Imagen en la que se puede comparar "encapsulados" de

Darío Villalba, de la reciente exposición en la sala del Cubo del Kursal de San Sebastián, con gráficos del artista incluidos en la encuesta del G.E.T.C.R.A.C., realizada en 1990

4 y 5. Imágenes del vídeo realizado en el taller del artista Iñaqui Cerrajería (Vitoria, 1996) que muestran distintos detalles del taller, los materiales y la técnica de trabajo de dicho artista.
Diputación Foral de Alava a los artistas con obra en la colección del Museo de Bellas Artes de Vitoria, la realización de una Base de Datos sobre técnicas y criterios de conservación de los artistas contemporáneos. La mayor aportación de este proyecto a las anteriores iniciativas es la importancia otorgada a la opinión de los artistas. Mientras que la mayoría de los cuestionarios no conceden demasiada importancia al artista en la toma de decisiones de restauración, en nuestro caso, haciéndonos eco de la filosofía de la Ley de Propiedad Intelectual española, se dedica casi media encuesta a que el artista defina y establezca sus preferencias o criterios.

Este tipo de Bases de Datos tiene una utilidad múltiple. Su primera finalidad es recoger una información que podrá utilizarse en caso de tener que realizar intervenciones de conservación-restauración sobre las obras de determinado artista. También se pueden desarrollar estudios sobre la técnica de un artis- ta, sobre un grupo, generación o escuela. Permite la realización de revisiones comparadas o estadísticas, tanto de los aspectos técnicos como de las opciones sobre conservación. Se puede analizar la utilización de materiales o técnicas concretos, etc. Datos que pueden incluirse o ser el objeto de trabajos de investigación, tesis doctorales o artículos, por ejemplo.

Evidentemente los trabajos o revisiones comparadas deben estar sometidos a todo tipo de prudencias, ya que la extensión y concreción de cada encuesta depende de la voluntad del artista en cuestión. Así en algunos casos contamos con mucha información acompañada de gráficos complementarios (Foto 3) y en otros el artista se ha limitado a marcar con una cruz en las casillas prefijadas.

La respuesta de los artistas a este tipo de cuestionarios es por lo general buena, pero por experiencia sabemos que es más eficaz que un restaurador esté presente, mientras éste rellena el cuestionario, para aclararle las dudas que puedan plantearle las distintas preguntas e intentando que no se limite a dar información genérica y especifique al máximo marcas de productos, recetas de preparación, fechas de utilización, etc. El restaurador además puede retener o anotar anécdotas o casos interesantes para incluirlos en la Base de Datos.

En la actualidad contamos con un fondo de 230 encuestas realizadas, que han venido siendo consultadas periódicamente por profesionales y estudiantes de restauración. Se han publicado también algunos trabajos con datos generales ${ }^{4}$, pero tras la publicación de la Ley Orgánica 15/1999, de 13 de diciembre de Protección de Datos de Carácter Personal, la utilización de la Base de Datos está limitada hasta que obtengamos de los distintos artistas su autorización, lo que supondrá un periodo de tiempo relativamente largo.

\section{Vídeos}

Otro sistema de documentación que puede tener una gran utilidad en el futuro es la grabación en formato vídeo del artista durante su trabajo. Hemos realizado ya alguna experiencia de este tipo (Fotos 4 y 5) y en la actualidad estamos desarrollando un proyecto ${ }^{5}$ que refleje dónde y cómo los artistas se enfrentan a la ejecución de la obra. En estos vídeos se recogerá en un formato de documental, de corta duración, los distintos aspectos que intervienen en la realización de una obra: contexto de trabajo, tipo de taller, materiales y técnicas que utiliza, fases de ejecución, trayectoria del artista, con la inclusión de comentarios sobre sus preferencias, criterios en cuanto al uso y la conservación de sus obras, etc.

Su finalidad última es la creación de un fondo documental que permita a estudiosos y especialistas conocer la naturaleza de las obras, sus procesos de elaboración, etc. para poder, en el futuro afrontar mejor los procesos de restauración y los criterios de conservación. Los destinatarios lógicos no debe- 
rían ser otros que los que los museos o centros de Arte Contemporáneos, los departamentos de Conservación-Restauración de Arte Contemporáneo y las instituciones académicas que forman especialistas en Conservación-Restauración, Arte contemporáneo o Museología.

\section{Fuentes Documentales}

Por desgracia, en muchos casos esa fuente directa ya no existe. Cuando el artista haya fallecido es necesario recurrir a fuentes orales próximas a éste, como son los familiares directos, los colaboradores y amigos, además de revisar otras fuentes documentales como catálogos, entrevistas publicadas, correspondencia y escritos del artista. No nos debemos conformar pues con, la necesaria pero no suficiente, revisión de catálogos razonados o estudios históricos o críticos sobre éste.

Una vez fallecido el artista, cuestionarios como los del G.E.T.C.R.A.C. pueden alcanzar un importante valor documental. Así recientemente ante la restauración de una obra de Lucio Muñoz en el Museo de Bellas Artes de Bilbao, surgió una polémica sobre la conveniencia o no de barnizar la obra. Las especialistas del departamento de restauración presentaron, como argumento en contra, la encuesta realizada al artista en 1988 por Ana Sánchez Lasa, en la que éste manifiesta claramente: "si a un cuadro mate, que son casi todos, le dan brillo, preferiría romperlo", con lo que la cuestión quedó zanjada.

Otra importante fuente documental son las fotografías publicadas en libros y revistas o pertenecientes a la familia, en las que se pueda ver su lugar de trabajo, los materiales que manejaba y las obras en proceso de creación. Igualmente hay que revisar las películas o vídeos familiares y los documentales sobre el artista, en los que se puedan observar estos detalles.

Este tipo de documentos que, aunque desde otro punto de vista, suelen ser analizados por los historiadores y críticos de arte, han de ser tenidos en cuenta también por los restauradores, ya que pueden ofrecer pistas o informaciones claras de los materiales y técnicas empleados por el artista, sus referencias estéticas o sus planteamientos conceptuales. Aspectos todos ellos que, como hemos insistido, pueden determinar la intervención del restaurador.

\section{Estudios Técnicos}

La recogida sistemática de información técnica, contrastada mediante el debido rigor y metodología cientíícos, es una de las vías de documentación tradicionales sobre las obras de arte. Se utilizan en la actualidad numerosas técnicas físicas o químicas y métodos analíticos y documentales que nos permiten contrastar datos sobre obras antiguas o modernas.

\section{Estudios sobre la técnica de un artista}

Uno de los sistemas habituales para el conocimiento de las características técnicas de la producción de artistas fallecidos, es la realización de diversos estudios de sus creaciones. Para llegar a conclusiones generales fiables, es necesario contar con una muestra de obras suficientemente amplia, no basta con el estudio de una sola pieza, y estudiar la técnica desde distintos ángulos de enfoque y con distintos métodos analíticos. A pesar de su interés, los inconvenientes para la realización de este tipo de estudios pueden ser muchos. Por un lado los costes de los análisis químicos y los estudios radiográficos y reflectográficos son muy elevados. Por otro lado los análisis químicos, aunque mínimamente, son destructivos, por lo que no se pueden tomar muestras indiscriminadamente. También hay que tener en cuenta la complicación para acceder a un número de obras suficiente, etc.

Estudio De La Técnica De Juan De Echevarría: Como ejemplo de este tipo de estudios podemos citar uno que hemos llevado a cabo recientemente, a petición de la historiadora Verónica Mendieta, que estaba realizando el catálogo razonado del artista6. En este trabajo se han analizado las telas de los soportes de 30 obras, se han analizado igualmente los pigmentos y aglutinante de los colores de la paleta del artista, se han revisado varias obras con Reflectografía Infrarroja y una de ellas además mediante Rayos X (Foto 6).

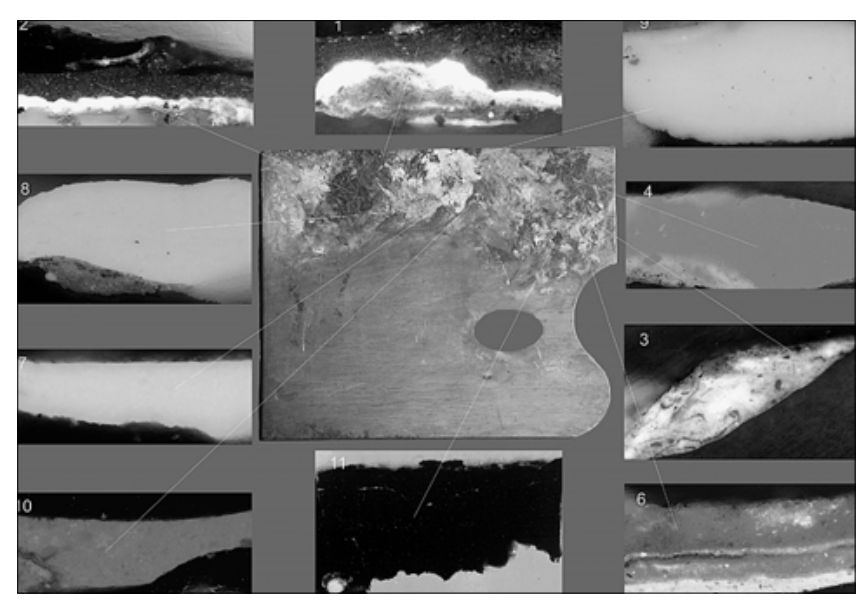

Como consecuencia de ello, podemos deducir que trabajaba fundamentalmente sobre soportes de lino de trama muy fina, aunque esporádicamente utilizara telas de algodón, lino-algodón, lino-cáñamo o yutealgodón, muchos de procedencia francesa, que realizaba un encaje sencillo y grueso realizado al óleo con azul o negro, que no empastaba demasiado y utilizaba veladuras, aunque solía hacer correcciones de composición o encaje, coincidiendo éstas con frecuencia con los empastes y los craquelados prematuros. Bastantes obras han sufrido manipulaciones o "restauraciones" que sospechamos han podido ser realizadas dentro de la familia.

Una de las utilidades de este tipo de estudios generales es la de poder establecer algunas característi-
6. Imagen de la paleta de Juan de Echevarría con las estratigrafías de los colores analizados. Pigmentos modernos: Banco de Cinc, Amarillo Cadmio, Amarillo Estroncio, Rojo Cadmio, Violeta de Cobalto, Azul Cobalto, Azul Cerúleo, Verde Cromo, Rojo orgánico (sin definir exactamente). Pigmentos tradicionales: Albayalde, Tierras (Óxido de Hierro), Negro de Huesos. 


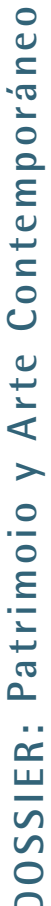

7. Detalles de las fibras, entre otras de celulosa regenerada, del cuadro identificado como falso.

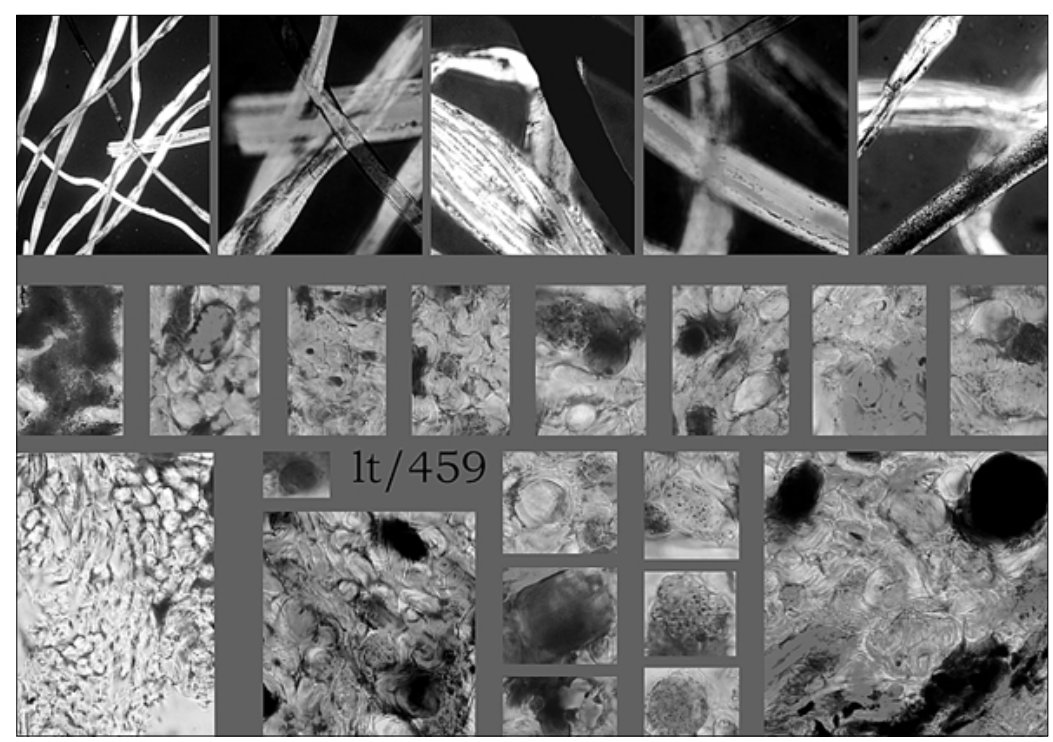

cas que, aunque con muchas reservas, permita identificar una obra como auténtica o no.

Así durante este estudio nos encontramos con una supuesta obra de Echevarría, perteneciente a una colección privada, realizada sobre un soporte de tela basta, que contenía una mezcla de fibras naturales y artificiales de celulosa regenerada. Aunque este tipo de fibras ya existiera en las fechas en que supuestamente habría sido realizada la obra, podemos descartar su autenticidad (Foto 7). Para ello nos basamos por un lado en la tela en cuestión, de muy baja calidad, elaborada a partir de restos de producción como las utilizadas para rellenos y forros interiores de tapizado de muebles. En aquella época se comercializaban soportes baratos para pintura pero no de este tipo. La desahogada situación económica del artista hace descartar que recurriera a este soporte. Por otro lado, sus preferencias sobre la composición para la pintura, confirman la importancia, el respeto que tenía por estas cuestiones y la concepción hasta cierto punto clásica, incompatible con la utilización de cualquier material, que también se puede corroborar con algunas de sus afirmaciones ${ }^{7}$.

Uno de los problemas que se presenta en la actualidad es el de la abundante incorporación de nuevos materiales, introducidos en el mercado por una desbordante producción industrial. Esto nos obliga a conocer la diversidad de estos productos, el modo de incorporación al panorama material del arte moderno y su comportamiento en el tiempo. Para ello es necesario realizar estudios sistemáticos sobre grupos de productos, intentando obtener respuestas a estas cuestiones. Una ardua labor, que requiere por lo general tiempo y dinero para medios materiales y humanos, pero que se pueden compensar en ocasiones con una recopilación de información sistemática.

Una cuestión clave de este tipo de trabajos es la coherencia de la metodología empleada en cada caso. Dependiendo de los cuadros profesionales y de los y textura de las telas y de los materiales que utilizaba

.
talmente de las colecciones alavesas, pero también de otros museos y colecciones ${ }^{8}$ y algunas que aparecen en bibliografía, identificadas de forma fiable.

Si bien tenemos que guardar ciertas reservas, por lo heterogéneo de los grupos de estudio, con esta información podemos hacer distintos análisis generales o estadísticos, establecer porcentajes, conocer la evolución histórica o establecer las siguientes generalidades o tendencias:

- Los soportes tradicionales de lino raramente se mezclan con otros tipos de fibra y cuanto más modernos son de mejor calidad. Los de algodón, incorporados poco a poco desde finales del XIX, presentan en más de la mitad de los casos mezclas de fibras, de lino los más antiguos y de poliester los más recientes. Los que presentan fibras artificiales o sintéticas, casi siempre van con mezclas?. 
- Hay dos tendencias que se hacen patentes con el paso del tiempo: el aumento de las telas con algodón y el de las telas con mezclas de fibras, en las que el algodón suele ser una de ellas.

- Parece existir un paralelismo entre la evolución de la historia de los textiles y la composición de las telas de los artistas. Marcando la presión de la industria y el mercado en el mundo artístico.

- Las fibras artificiales y sintéticas se van incorporando a los soportes artísticos, con un pequeño desfase cronológico, tras su comercialización y se empiezan a generalizar desde mediados del siglo XX.

- En determinadas épocas de escasez de materias primas, aumenta el uso de telas de menor calidad o de sustitutivos 10 y algunos artistas utilizan telas de baja calidad por su escaso poder adquisitivo.

- Muchos artistas, que han utilizado telas con mezcla de fibras sintéticas, pretendían utilizar lonetas de algodón, imitando a artistas americanos del Expresionismo Abstracto, el Pop-Art, el Op-Art, etc.

- En ocasiones resulta difícil explicar el porcentaje de utilización de algunas fibras como el yute a finales del XIX y principios del XX, ya que coinciden periodos de escasez, problemas económicos de los artistas y ciertas preferencias estéticas "I.

Como se puede ver, son numerosas las consideraciones que se pueden hacer y las conclusiones que se pueden extraer a partir de un estudio sencillo pero sistemático, sin grandes medios o equipamiento. Una labor constante o un programa de recogida de datos a largo plazo permite establecer conclusiones y aumentar nuestros conocimientos sobre las obras a tratar.

\section{Estudio sobre los poblemas de Conservación del} "Peine del Viento"

Presentamos el caso de esta escultura de Chillida ${ }^{2}$, como ejemplo de estudio más completo.

De acuerdo con el artista y con el Ayuntamiento de San Sebastián realizamos diversos estudios sobre los problemas de conservación de la obra. Se analizaron muestras de fragmentos desprendidos y se compararon con otras en buen estado cedidas por el artista, determinando su composición. Aunque la muestra del "Peine del Viento" estaba muy oxidada y contaminada con otros materiales, en ambos casos se trataba de un acero de bajo contenido en carbono, débilmente aleado con $\mathrm{Cr}$, Ni y Cu, de similares características, pero no exactamente de acero "corten".

Primeras Pruebas "In Situ": Dada la imposibilidad de reproducir exactamente en laboratorio las condiciones reales, se quiso comprobar la eficacia de posibles tratamientos "in situ". Para ello se llevaron a cabo en 1993 unas pruebas sobre la escultura que consistieron en la realización de varios testigos en la pieza más alejada, con posteriores visitas de comprobación de su evolución. Se estableció un protocolo que incluía la realización de catas de limpieza por medios mecánicos, inhibición con ácido ortofosfórico, protección de las superficies con monocapa y bicapa (Paraloïd B72 y cera), dejando zonas testigo sin protección para comparar los resultados y reintegración de volumen en grietas con varios tipos de Araldit (Foto 8).

Los resultados indicaban un mejor comportamiento de las zonas protegidas con bicapa. No se observó ninguna diferencia entre las zonas tratadas y no tratadas con ácido ortofosfórico. En cuanto a las reintegraciones, en todos los casos mantenían buen aspecto y estaban bien adheridas, aunque algo blandas, quizá como consecuencia de la humedad.

Envejecimiento Artificial en Laboratorio: Esta fase del estudio tenía como finalidad comprender mejor los factores que intervienen, y en qué grado, en el deterioro del acero, también se pretendía conocer el comportamiento y eficacia de ciertos tratamientos. Partimos de las experiencias de otros especialistas 13 , realizando ensayos de envejecimiento artificial sobre muestras sanas de corten.

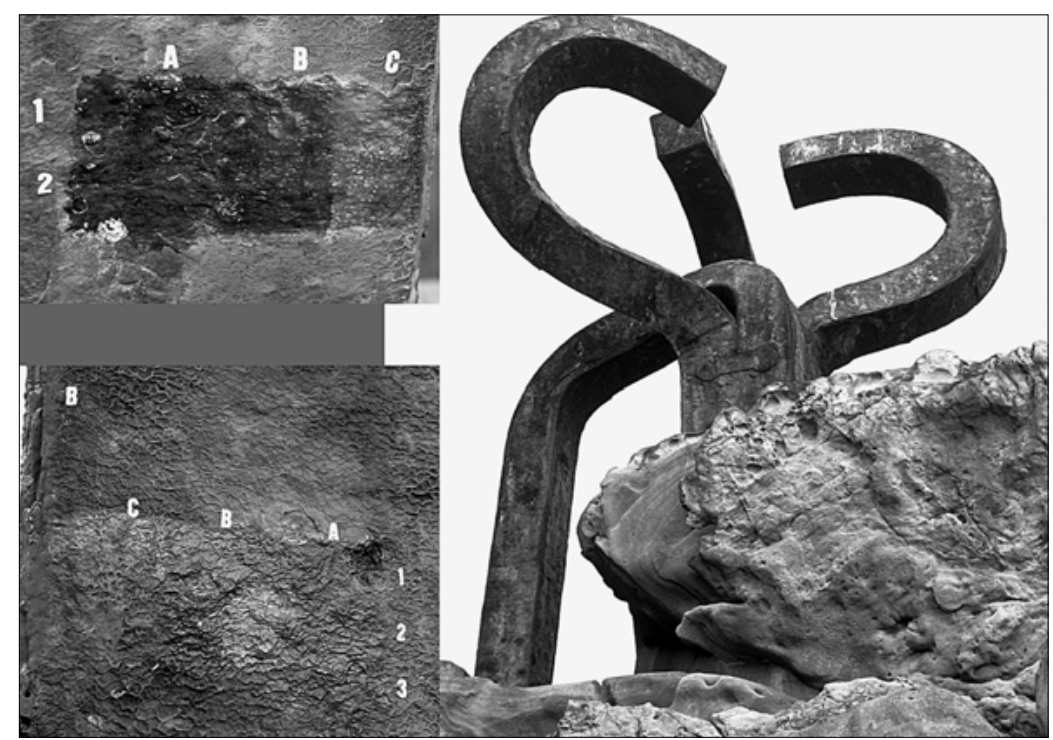

El protocolo de los ensayos consistió en la realización de probetas de $4 \times 4 \mathrm{~cm}$, limpiadas mediante chorreado de microesferas de vidrio de $5 \mu$ a presión y desengrasadas con acetona. Parte de ellas se recubrieron con cera microcristalina, otras con Paraloïd B48 $\mathrm{N}$ al 10\% en disolvente orgánico y otras con una bicapa (Paraloïd B48 N y cera microcristalina). Se prepararon igualmente probetas dobles adheridas con Araldit Rápido y otras con ánodos de sacrificio de "zincoline" (del 5 \% del peso de la probeta) para protección catódica. Todas ellas junto con otras "probetas testigo" se dividieron en grupos y se sometieron en laboratorio a los siguientes test: Ultravioletas, Niebla Salina, Choque Térmico, Inmersión y Simulación de Condiciones Reales (Foto 9).
8. Catas realizadas en la pieza más alejada de la escultura de Chillida el "Peine del Viento" en San Sebastián. 


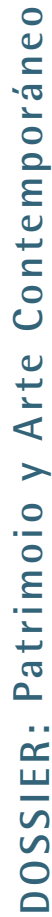

9. Imágenes de los equipos y probetas de los ensayos en laboratorio para el estudio del "Peine del Viento".

I. Niebla Salina, 2. Inmersión, 3. U. V. 4. Choque térmico. 5. Simulación de condiciones reales

10. Imágenes de las condiciones del entorno y de algunas probetas, antes y después del ensayo de protección catódica "in situ", del estudio del "Peine del Viento".
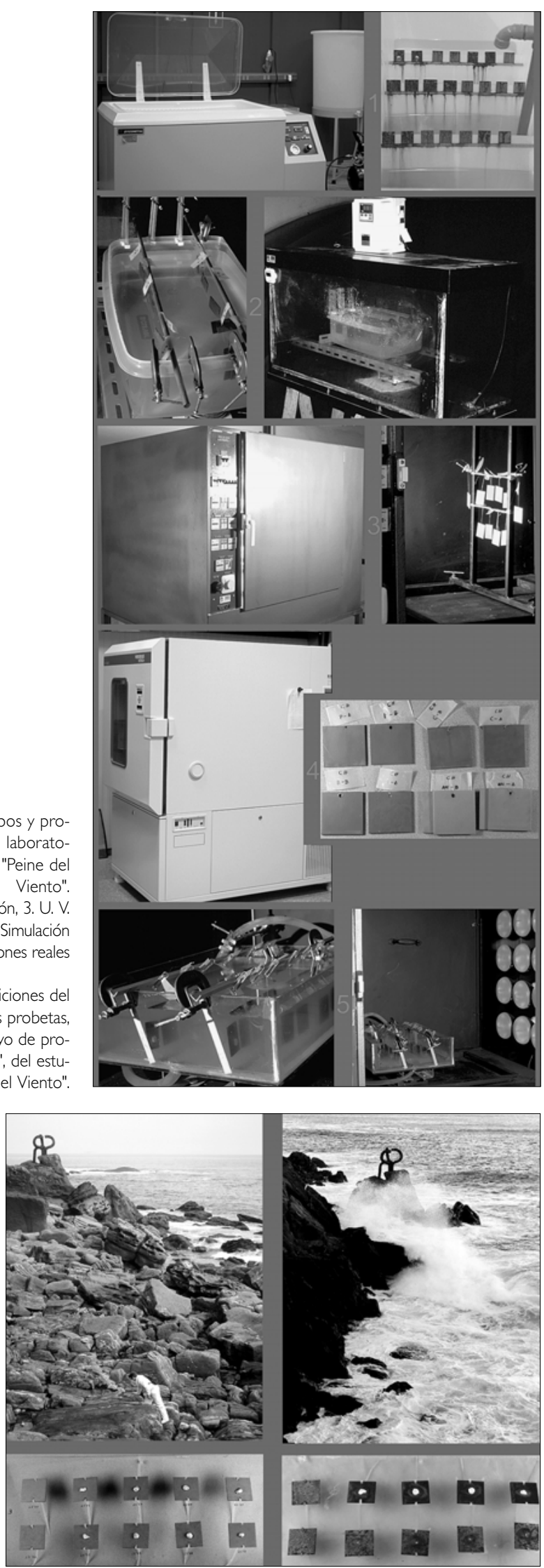

El estudio indicó que las protecciones con bicapa muestran unos resultados aceptables, superiores a los de protecciones con una sola capa. La diferencia entre las probetas sin protección y las protegidas con bicapa es de casi el $40 \%$ en el ensayo de Niebla Salina, de más del $80 \%$ en el de Inmersión y de casi el $100 \%$ en el de Simulación de condiciones. Lo que supone una protección mínima del 40 \%, que se puede considerar aceptable. Los ánodos de sacrificio de "zincoline" han dado buenos resultados en el ensayo de Simulación, dudosos en el de Inmersión y francamente malos en el de Niebla Salina. Los resultados demuestran que la exposición en atmósfera salina es la situación más agresiva, más destructora que la inmersión en agua salada y mucho más que en condiciones de simulación. La exposición a radiaciones ultravioletas afecta a la protección de paraloïd. Las radiaciones Ultravioletas, la alta temperatura y el contacto con el agua parece afectar en parte a la resina de Araldit, aunque es difícil decir hasta qué punto.

Pruebas De Protección Catódica Realizadas "In Situ": Posteriormente se desarrolló un plan de ensayos "in situ", para evaluar el grado de eficacia de la protección catódica en las condiciones reales de la escultura, colocando en el entorno cuatro grupos de probetas (Foto 10)

El protocolo de los ensayos consistió en la preparación de probetas de $4 \times 4 \mathrm{~cm}$ de acero corten sano, limpiadas mediante chorreado de microesferas de vidrio de $5 \mu$ a presión. La mitad de ellas se sometieron a un granallado industrial, para crear una superficie más rugosa. Se les aplicó posteriormente ánodos de sacrificio de "zincoline" (del $5 \%$ del peso de la probeta), dejando parte de éstas sin protección, como testigos. Se distribuyeron cuatro baterías en distintas zonas expuestas a distintas circunstancias: inmersión completa, inmersión temporal dependiendo de las mareas, exposición al oleaje y humedad ambiente con aerosol salino, cada una de ellas con 10 probetas, cinco granalladas y otras cinco sin granallar. En cada batería 8 probetas van con ánodos de sacrificio y 2 son testigos, en total 40 probetas, 32 con ánodos y 8 testigos.

Los resultados, aunque condicionados por la pérdida de varias probetas y ánodos por la fuerza del mar (hubo que repetir el ensayo mejorando los sistemas de anclaje) indican, tras una exposición durante más de 400 horas, que la protección catódica parece funcionar correctamente en condiciones de inmersión completa, tiene algún efecto en condiciones de inmersión en función de las mareas y de exposición al oleaje, pero no parece funcionar ante la humedad ambiente y el aerosol salino. Lo que confirma los planteamientos excépticos de algunos especialistas consultados.

De cualquier forma, en el caso del "Peine del Viento", la aplicación de capas de protección, supondría la eliminación completa del óxido de la superficie y la modificación de los tonos con un oscurecimiento generalizado y la aparición de brillos, algo que desagrada al artista ${ }^{14}$. No parece existir pues ningún método de protección eficaz que impida su lento deterioro, en aquél entorno. 
1. RUIZ DE ARCAUTE, E. Conservar el arte contemporáneo, un reto de hoy. LAPIZ, n ${ }^{\circ 4}$, Madrid, octubre de 1987. p. 37-40.

2. BUSTINDUY, P. Proyecto de restauración del Bosque de Oma de Agustín Ibarrola. Comunicación presentada en la Reunión del Grupo de Contemporáneo del GE-IIC. Madrid, febrero de 2001 .

3. Podemos citar los casos de la Restarurierungcentrum Fundation Henkel de Düsseldorf, el de la Western Association of Art Conservators de las Ängeles, el del Walker Center de Mineápolis, el del Museum of Contemporary Art de Chicago, la de La Burnaby Art Gallery, el del GSA Art-in-Architecture, el del Brooklyn Museum de Nueva York, el del Ralph Mayer Center-University of Delaware, el del Museum and Art Gallery de Birmingan o los trabajos de CUMMINGS, L. It is not a trend; It is an inevitability... Interviews with nine contemporary artists. International Symposium on the Conservation of Contemporary Art; July 7-12, 1980; Ottawa. y GOFFETTE, I. Dix peintres belges contemporains: leurs matériaux, leurs techniques picturales en vue de la conservation de leurs oeuvres. Trabajo de fin de estudios de l'Ecole Nationale Supérieure des Arts Visuels (La Cambre), año escolar 1984-1985.

4. RUIZ DE ARCAUTE, E. El problema de la restauración en el Arte Contemporáneo. Encuesta del Servicio de Restauración de la Diputación Foral de Alava. CYAN, n 8. Madrid, febrero 1988. p. 31.

PARDO, D. Y ARANSAY, C. Resultados parciales de las encuestas realizadas por el grupo de trabajo a artistas contemporáneos. G.E.T.C.R.A.C. Comunicaciones de la $2^{\mathrm{a}}$ Reunión de Trabajo. Madrid, 9 de abril de 1990. p. 17-24. ABALIA, K.; BARRIO, M.; BERASAIN, I. Y OKARANZA, R. Tratamiento informático de las encuestas sobre técnicas y criterios de restauración y conservación de artistas contemporáneos. G.E.T.C.R.A.C. Comunicaciones de la $3^{\mathrm{a}}$ Reunión de Trabajo. Vitoria, 21 - 22 de noviembre de 199|. p. 81-88. RUIZ DE ARCAUTE, E. Creación de una Base de Datos sobre las técnicas de los artistas contemporáneos y sus criterios en materia de Conservación y Restauración G.E.T.C.R.A.C. Comunicaciones de la $3^{\mathrm{a}}$ Reunión de Trabajo. Vitoria, 21 - 22 de noviembre de 1991. p. 89-97.

RUIZ DE ARCAUTE, E. Base de Datos sobre las técnicas de los artistas contemporáneos y sus criterios en materia de Conservación y Restauración. Boletín Informativo del IAPH, $\mathrm{n}^{\circ}$ 3. Sevilla, junio de 1993. p. 5-6.

RUIZ DE ARCAUTE, E. Opinión De Los Artistas Frente a La Restauración. Comunicación presentada en el IOth Triennial Meeting. ICOM. Comitte for Conservation. Washington, 1993.

RUIZ DE ARCAUTE, E. Opinión De Los Artistas Frente a La Restauración. G.E.T.C.R.A.C. Comunicaciones de la $4^{\text {a }}$ Reunión de Trabajo. Barcelona, 18-19 de febrero de 1994. p. | $17|3|$.

5. Se trata de un proyecto de José Carlos Roldán (Centro Andaluz de Arte Cantemporáneo) y Emilio Ruiz de Arcaute (Servicio de Restauración de la Diputación Foral de Alava) que se ha presentado en la última Reunión del Grupo de Arte Contemporánreo del GE-IIC, Madrid, febrero de 200I.

6. RUIZ DE ARCAUTE, E. Estudio de la técnica de Juan de Echevarría. (1875-193I). Comunicación presentada en la Reunión del Grupo de Contemporáneo del GE-IIC. Madrid, febrero de 2000

7. "Que una sociedad que fundaron Manet, Monet y Renoir con un país grande y noble, con el fin de mostrar a los ojos del mundo una nueva fase del Arte, una nueva visión de la vida sincera, fuerte, haya caído en lo banal y en lo ridículo, y sobre todo, que una cosa sagrada como es la pintura, el óleo, lo hayan convertido en bufón del pueblo,..." fragmento tomado de la carta de 20-3-1903 a su amigo Manuel Losada en GONZÁLEZ DE DURANA, J. Tres Cartas de Juan de Echevarría a Manuel Losada. Kobie. Bellas Artes, n8, Bilbao, 1991. D.F.B. p.86.
8. Museo de Bellas Artes de Bilbao, Diputación Foral de Vizcaya, Centro Reina Sofía de Madrid, Fundació La Caixa de Barcelona, Centro Andaluz de Arte Contemporáneo de Sevilla, MACBA de Barcelona y numerosas colecciones privadas).

9. Un ejemplo extemo lo encontramos en la tela de la obra titulada "Retrato de un artista joven" de Galanda, que presenta una mezcla de numerosas fibras artificiales y sintéticas junto con algodón. Ver RUIZ DE ARCAUTE, E. Estudio de soportes de tela contemporáneos. G.E.T.C.R.A.C. Comunicaciones

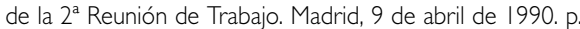
54 - 55. También se puede consultar RUIZ DE ARCAUTE, E. Trabajo de investigación sobre soportes de tela modernos y contemporáneos, comunicación presentada en la $5^{a}$ Reunión del G.E.T.C.R.A.C. Vitoria, septiembre de 1996.

10. Hay que destacar la incidencia del desarrollo de la industria textil del XIX, en torno al algodón, en la progresiva aparición de esta fibra en las telas de artistas que trabajaron a caballo de los siglos XIX y XX. Se tiene constancia de la inclusión de estas fibras en soportes para artistas (Lefranc and Cie. incluye en su catálogo de 1855 la denominada "Madapolan toile" de algodón para pintura al pastel, en el catálogo de G. Sennelier aparece en 1894 y en el de Lefranc en 1896 una tela de algodón para óleo, Windsor and Newton introduce las telas de algodón entre 1900 y 1906, en el catálogo de esta marca de 1906 aparece citada como "good serviceable cloth of English manufacture" y en el de 1928 ya se especifica como de algodón, en 1907 Rowney and Co. presenta una tela mitad lino mitad algodón y en 1936 ya presentaba dos telas de este tipo, "Quality S" y "Quality V", Windsor and Newton introduce también una tela mezcla de lino y algodón en 1935 con la denominación "NP Range"). Ver:

VILLERS, C. Artists Canvases. A History, en Worqung Group Structural Restoration of Canvas Paintings. ICOM. Committee for Conservation. 6th Triennial Meeting. Ottawa, 1981. p. $8 \mid / 2 / 1-8-1-9$

CALLEN, A. Técnicas de los impresionistas. Hermann Blume Ediciones. Madrid 1983. pag. 59.

HARLEY, R. D. Artists' Prepared Canvases from Winsor \& Newton 1928 - 1951 en Studies in Conservation, vol. 32, $n^{\circ} 2$ IIC, Londres, mayo, 1987. p. 77 - 85.

II. Puede ser esclarecedor en este sentido que en 1913 Rowney and $\mathrm{Co}$. comercializara una tela de yute denominada "Quality H", que Winsor and Newton introdugera en el mercado una tela de yute en 1920, cuya producción cesa en 1948, o que en 1936 Rowney presentara bajo la denominación de "Quality M" una mezcla de lino y yute, por ejemplo. VILLERS, C. Op. Cit. p. 8I/2/I-7.

12. RUIZ DE ARCAUTE, E. Étude pour la protection d'une sculpture en 'corten'. Possibilités et limites de la protection cathodique. Metal 98. Actes de la Conférence Internationale sur la Conservation des Métaux. Draguignan, may 1998. p.280-285.

13. KEENE, S. Thje performance of coatings and consolidants used for archeological iron. Adhesives and Consolidants. IIC, Presprints of the Contributions to the Paris Congress, 2-8 September 1984. pp. 104 - 106. MOUREY, W. Etude comparee de la resistance a divers formes de corrosion des revetements protecteurs utilises en conservation des metaux. ICOM, 8th Triennial Meeting. Sydney, Australia. 6-II September 1987. pp. I087 - 109I. MOUREY, W. et CZERWINSKI, E. Essais comparatifs de revêtements protecteurs utilisés en conservation et restauration des métaux. ICOM, 10th Triennial Meeting. Washington, DC, USA. 22-27 August 1993. pp. 779 - 785. MOUREY, W. La protection des grosses pieces metalliques par creation d'un cuple galvanique, avenir ou utopie?. ICOM, 9th Triennial Meeting. Dresden, German Democratic Republic. 26-3I August 1990. pp. 745 - 747.

14. Contamos con la encuesta del G.E.T.C.R.A.C., realizada en 199|. Pero por otro lado hemos mantenido diversos contactos personales con el artista, en los que se ha podido ampliar la información sobre estos detalles. 